\title{
Method Development and Validation for Desogestrel and Ethinylestradiol in Combined Pharmaceutical Dosage Form by RP-HPLC
}

Sanjay Bais ${ }^{1 *}$, Anil Chandewar ${ }^{2}$, Imran Popte ${ }^{2}$, Indrajeet Singhvi ${ }^{3}$ and Khemchand Gupta ${ }^{3}$

${ }^{1}$ Research Scholar, PRIST University, Thanjavur-Tamilnadu, India

${ }^{2} P$ Wadhwani College of Pharmacy, Yavatmal-MS, India

${ }^{3}$ Pacific College of Pharmacy, Udaipur, Rajasthan, India

\begin{abstract}
A simple, rapid, sensitive RP-HPLC method for the simultaneous determination of Desogestrel and Ethinyloestradiol in pharmaceutical dosage forms was developed the analyte were resolved using $\mathrm{KH}_{2} \mathrm{PO}_{4}$ Buffer (0.02M): Acetonitrile (50:50), at a flow rate of $2.0 \mathrm{ml} / \mathrm{min}$, on HPLC auto sampler system containing UV- visible and fluorescence detector with Empower software and Zorbax SB Phenyl C18 column $(4.6 \times 150 \mathrm{~mm})$. Detector Fluorescence detector for Ethinylestradiol UV detector for Desogestrel, For the estimation the detection wavelength was taken as $310 \mathrm{~nm}$ Emission and $285 \mathrm{~nm}$ excitation Ethinyloestradiol and $210 \mathrm{~nm}$ for Desogestrel. Linearity for detector response was observed in the concentration range of $10-150 \%$ of test concentration. Correlation coefficient $(r)$ for calibration curve was found to be 1.0. Retention times were found to be $2.4 \mathrm{~min}$ and $13.9 \mathrm{~min}$ for Ethinyloestradiol and Desogestrel respectively. Percent recovery was found to be within the range of $98.0 \%$ to $102.0 \%$. The percent RSD for the analyzed tablet and recovery studied was less than 2 . The results of recovery studies were found to be linear in the range $50 \%$ to $150 \%$ of test concentration. Results of the analysis were validated statistically and by recovery studies. The developed method was found to be precise, selective and rapid for the simultaneous determination of Desogestrel and Ethinyloestradiol in bulk and in pharmaceutical dosage form.
\end{abstract}

Keywords: Desogestrel; Ethinyloestradiol; Reversed-phase HPLC; Validation

\section{Introduction}

Desogestrel is chemically, 13-Ethyl-11-methylidene-18, 19-dinor17a-pregn-4-en-20-yn-17-ol having Molecular Formula and Molecular Weight $\mathrm{C}_{22} \mathrm{H}_{30} \mathrm{O}$ and 310.5 respectively. It is white to offwhite, crystalline solid with a pKa of 13.04 , slightly soluble in acetone and ethanol (95\%) It belongs to Contraceptives category [1].

Ethinyloestradiol Chemically is 19-Nor-17a-pregna-1, 3, 5(10)-trien-20-yne-3, 17-diol having Molecular Formula and Molecular weight $\mathrm{C}_{20} \mathrm{H}_{24} \mathrm{O}_{2}$ and 296.40 respectively. It is White crystalline powder, freely soluble in alcohol; with $\mathrm{pKa} 17.59$.It also belongs to Contraceptives category. It is mainly used in hormone therapies for androgen dependent disorders, acne, hirsutism, seborrhea. Recently it is shown that, the continuous daily ovarian activity and eliminate cyclic fluctuations in estradiol [2,3], progesterone, luteinizing hormone and follicle-stimulating hormone [4]. In addition, the combination of these drugs was used as an oral contraceptive for female patients with androgenic symptoms [2]. In the present research the attempt has been made to use two detector linearly for both drugs (Figure 1).

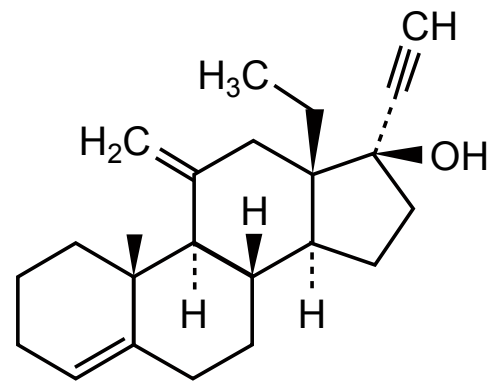

Figure 1a: Structure of Desogestrel.<smiles>C#C[C@]1(O)CC[C@H]2C3CCc4cc(O)ccc4[C@H]3CC[C@@]21C</smiles>

Figure 1b: Structure of Ethinylestradiol

Literature survey reveals that several methods were reported for estimation of like HPLC [3-11], RPHPLC [12,13]. Derivative spectrophotmetry [14], LC [15], HPLC-MS [16,17] Colorimetry [18].

\section{Experimental Work}

\section{Instrumentation}

The HPLC of Waters Alliance ID:-FCLS/Q/78 Detector UV 2487 and Fluorescence 2475 was used .The $\mathrm{pH}$ Meter, $\mathrm{pH}$ Tutor, Cyber Scan, Balance Sartorious \& Mettler Toledo UV-Visible Spectrophotometer, Varian Single beam were other equipments used during the research work.

*Corresponding author: Sanjay Bais, Research Scholar, PRIST University, Thanjavur-Tamilnadu, India, E-mail: sanjaybais@rediffmail.com

Received March 01, 2013; Accepted July 15, 2013; Published August 13, 2013

Citation: Bais S, Chandewar A, Popte I, Singhvi I, Gupta K (2013) Method Development and Validation for Desogestrel and Ethinylestradiol in Combined Pharmaceutical Dosage Form by RP-HPLC. Pharm Anal Acta 4: 262. doi:10.4172/2153-2435.1000262

Copyright: (c) 2013 Bais S, et al. This is an open-access article distributed unde the terms of the Creative Commons Attribution License, which permits unrestricted use, distribution, and reproduction in any medium, provided the original author and source are credited. 
Citation: Bais S, Chandewar A, Popte I, Singhvi I, Gupta K (2013) Method Development and Validation for Desogestrel and Ethinylestradiol in Combined Pharmaceutical Dosage Form by RP-HPLC. Pharm Anal Acta 4: 262. doi:10.4172/2153-2435.1000262

Page 2 of 7

Determination of wavelength maxima and calibration curve by using ultraviolet visible spectroscopy

Stock Solution of Ethinyloestradiol: Accurately weighed quantity $(3.75 \mathrm{mg})$ of Ethinylestradiol was transferred to $50.0 \mathrm{ml}$ volumetric flask, $30 \mathrm{ml}$ of diluent was added and sonicated to dissolve the drug and diluted up to the mark with diluent (Concentration $125 \mathrm{mcg} / \mathrm{ml}$ ).

\section{Desogestrel stock standard solution:}

Stock solution of desogestrel: Accurately weighed quantity (15 $\mathrm{mg}$ ) of Desogestrel was transferred to $20 \mathrm{ml}$ volumetric flask, $5 \mathrm{ml}$ of diluent was added and sonicated to dissolve the drug.About $2 \mathrm{ml}$ of Ethinylestradiol stock solution was added and mix well, diluted up to the mark with diluent. (Conc. of Desogestrel is about $6000 \mathrm{mcg} / \mathrm{ml}$, conc. of Ethinyloestradiol is about $125 \mathrm{mcg} / \mathrm{ml}$ ).

\section{Determination of wavelength maxima for Ethinylestradiol}

The aliquot portions of stock standard solutions of Ethinylestradiol were diluted appropriately with solvent to obtain concentration $20 \mu \mathrm{g} / \mathrm{mL}$ of drug. The solutions were scanned in the range of $400-$ $200 \mathrm{~nm}$ in $1 \mathrm{~cm}$ cell against blank. The UV absorbance spectrum of and Ethinyloestradiol is shown in Figure 2. From the spectrum the wavelengths selected for estimation of Ethinylestradiol were $210 \mathrm{~nm}$ and $275 \mathrm{~nm}$.

\section{Determination of wavelength maxima for Desogestrel}

The aliquot portions of stock standard solutions of Desogestrel were diluted appropriately with solvent to obtain concentration 20 $\mu \mathrm{g} / \mathrm{mL}$ of drug. The solutions were scanned in the range of $400-200$ $\mathrm{nm}$ in $1 \mathrm{~cm}$ cell against blank. The UV absorbance spectrum of and Desogestrel is shown in Figure 3. From the spectrum the wavelengths selected for estimation of Desogestrel were $210 \mathrm{~nm}$ and $275 \mathrm{~nm}$.

\section{Study of Beer- Lambert law}

The aliquot portions of stock standard solutions of Desogestrel and Ethinyloestradiol were diluted appropriately with solvent to get a series of concentration between $5-50(\mu \mathrm{g} / \mathrm{ml})$ of Desogestrel and Ethinyloestradiol. Similarly aliquot portions of stock standard solutions were mixed and diluted to get series of concentration between $5-50 \mu \mathrm{g} / \mathrm{ml}$. The absorbance of each solution was measured at $275 \mathrm{~nm}$ and absorbance of Ethinyloestradiol only was measured $275 \mathrm{~nm}$ in 1 $\mathrm{cm}$ cell against solvent blank. The graphs plotted as concentration Vs absorbance at selected wavelengths are shown in Figure 4 and 5.

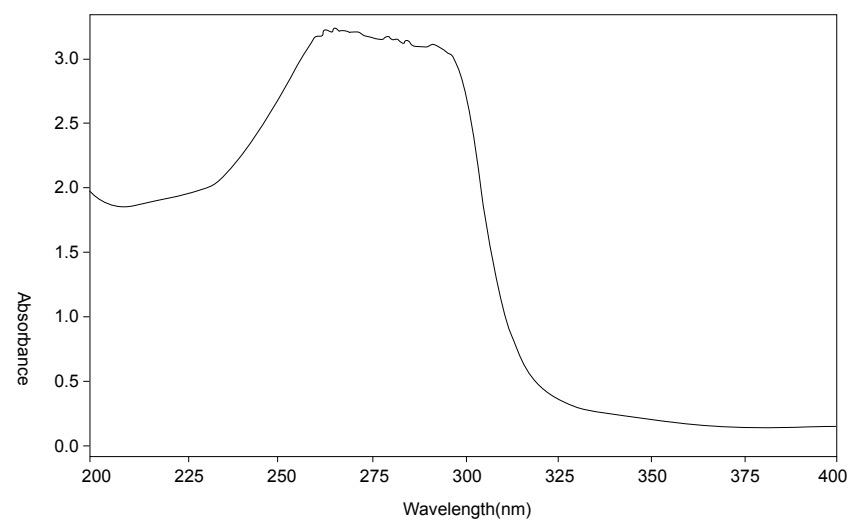

Figure 2: Spectra of Ethinyloestradiol.

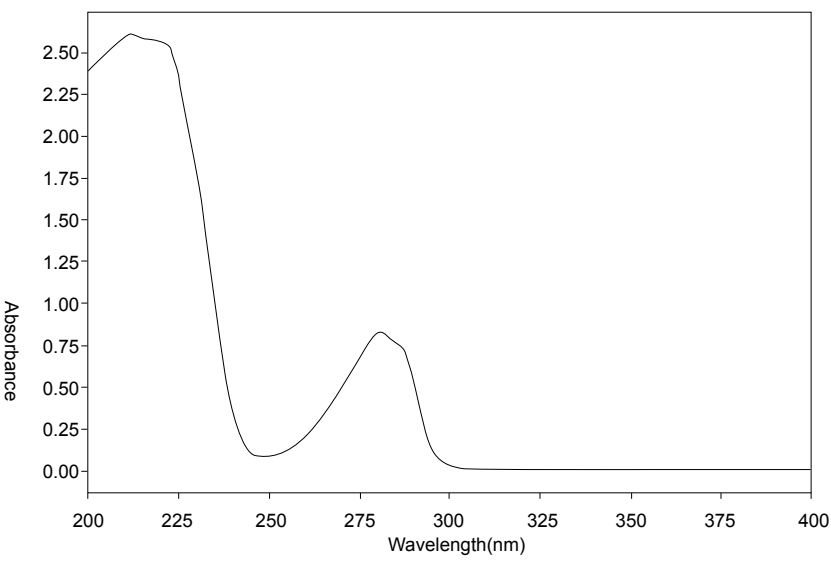

Figure 3: Spectra of Desogestrel.

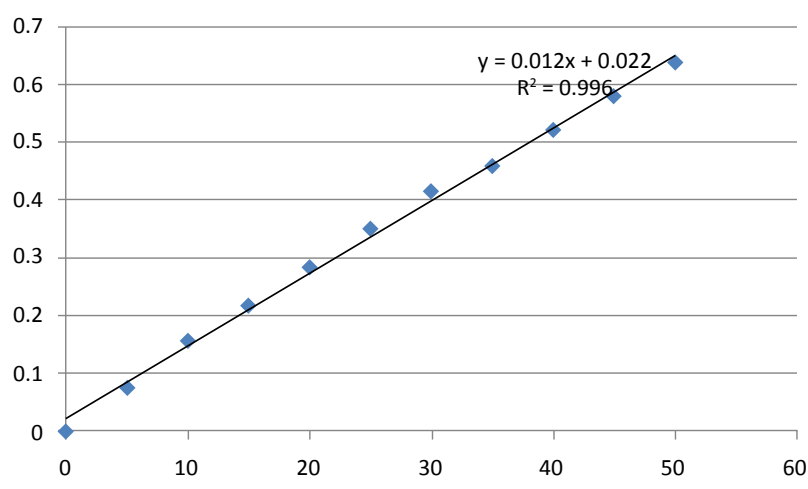

Figure 4: Plot of Beer-Lambert law forEthinyloestradiol at $275 \mathrm{~nm}$.

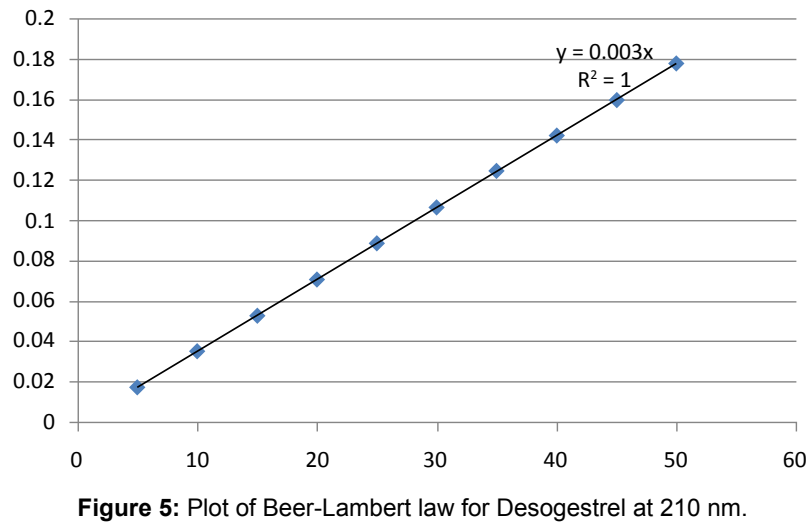

Selection of common solvent (Diluent): HPLC grade water and Acetonitrile of analytical reagent grade in the ratio of 50:50 v/v was selected as common solvent for developing Spectral characteristics of drug. The selection was made after assessing the solubility of both the drugs in different solvents.

\section{Preparation of standard stock solution:}

Stock Solution A: Accurately weighed $30.0 \mathrm{mg}$ of Desogestrel working standard accurately weighed and was transferred to $100.00 \mathrm{ml}$ volumetric flask, $70 \mathrm{ml}$ of acetonitrile was added and sonicated till the 
Citation: Bais S, Chandewar A, Popte I, Singhvi I, Gupta K (2013) Method Development and Validation for Desogestrel and Ethinylestradiol in Combined Pharmaceutical Dosage Form by RP-HPLC. Pharm Anal Acta 4: 262. doi:10.4172/2153-2435.1000262

Page 3 of 7

material completely dissolve. The volume was made with Acetonitrile and shaken. The $5.00 \mathrm{ml}$ of resulting solution was transferred to 100.00 $\mathrm{ml}$ volumetric flask, to volume was made with diluents.

Stock Solution B: About $30.0 \mathrm{mg}$ of Ethinyloestradiol working standard accurately weighed and was transferred to $100.00 \mathrm{ml}$ volumetric flask, about $70 \mathrm{ml}$ of acetonitrile was added and sonicated till the material was completely dissolved. The volume was made up to mark with Acetonitrile and shaken. The $5 \mathrm{ml}$ of resulting solution was transferred to $100.00 \mathrm{ml}$ volumetric flask. The final volume was made by using diluents (Figure 6).

\section{Selection of chromatographic condition for estimation of drugs}

In this method development and validation for Desogestrel and Ethinylestradiol mixture. The detection of Desogestrel was done by using UV detector and Ethinyloestradiol was done on fluorescence detector. The detection of both drug was not possible on same detector because Ethinyloestradiol quantity in the formulation was very less and it does not shows any peak on U.V. detector, that's why we had used fluorescence detector for Ethinyloestradiol detection which is linearly arranged with U.V. detector.

\section{Selection of mobile phase}

Standard stock solution A and B were appropriately diluted with diluents to obtain final concentration of Desogestrel and Ethinylestradiol, respectively. The standard solutions were injected into the HPLC system and run in different solvent systems. Mixture of different solvents were tried in order to determine optimum chromatographic conditions for effective separation of Desogestrel and Ethinyloestradiol. After several permutation and combination, it was found that mixture of Buffer, 0.01 M potassium dihydrogen phosphate buffer and Acetonitrile (50:50) gives satisfactory results as compared to other mobile phases. Finally, the optimal composition of the mobile phase, Buffer: Acetonitrile (50:50 v/v), and flow rate $2.0 \mathrm{ml} / \mathrm{min}$ showed good resolution, peak shape and desired elution. Retention time of Desogestrel was $13.9 \mathrm{~min}$ and that of Ethinylestradiol was $2.4 \mathrm{~min}$.

\section{Preparation of mobile phase}

The $500 \mathrm{ml}$ of potassium dihydrogen phosphate buffer and $500 \mathrm{ml}$ of acetonitrile was mixed in $1000 \mathrm{ml}$ glass bottle and filtered through $0.45 \mu \mathrm{m}$ membrane filter and degassed before use.

\section{Selection of analytical wavelength}

Standard stock solution A and B were injected separately to obtain extracted Chromatogram of Desogestrel and Ethinylestradiol. Each solution was scanned using PDA detector system and their Spectra were obtained. The wavelength selected was $210 \mathrm{~nm}$ as both the drugs showed significant absorbance at this wavelength.

\section{Optimized chromatographic conditions}

- Detector: Fluorescence detector for Ethinyloestradiol UV detector for Desogestrel

- Wavelength: $310 \mathrm{~nm}$ Emission and $285 \mathrm{~nm}$ excitation for Ethinylestradiol $210 \mathrm{~nm}$ for Desogestrel

- Column: Zorbax SB Phenyl C18 column (4.6 x 150 mm).

- Flow Rate: $2.0 \mathrm{ml} /$ minute

- Injection volume: $200 \mu \mathrm{l}$

- Run time: 20 minutes

- Retention Time: Ethinyloestradiol about 2.4 minute : Desogestrel about 13.9 minute

- $\quad$ Run Time: 20.0 min.

- Column Oven Temp: Ambient

- Sample Cooler Temp: Ambient

\section{Validation Program}

\section{System suitability}

Prepare the system suitability solution as per the proposed test method and inject into the HPLC system by following the instrumental condition as per the test method. Record the system suitability parameters observed into the following (Table 1) [19]

\section{Precision studies}

System precision: The standard solution was prepared as per test method and injected into the HPLC system in five replicates. The \% RSD was evaluated and the observations (Table 2).

Method precision: Six assay sample preparations from a single lot of Desogestrel and Ethinyloestradiol Tablets USP $(0.15 \mathrm{mg} / 0.03 \mathrm{mg})$ were made and analysed as per methodology. Content of Desogestrel and Ethinylestradiol in Desogestrel and Ethinylestradiol Tablets USP were calculated. L1 (Maximum allowed acceptance value) of Desogestrel and Ethinylestradiol in assay percentage of Desogestrel and Ethinylestradiol in six assay sample preparations was calculated

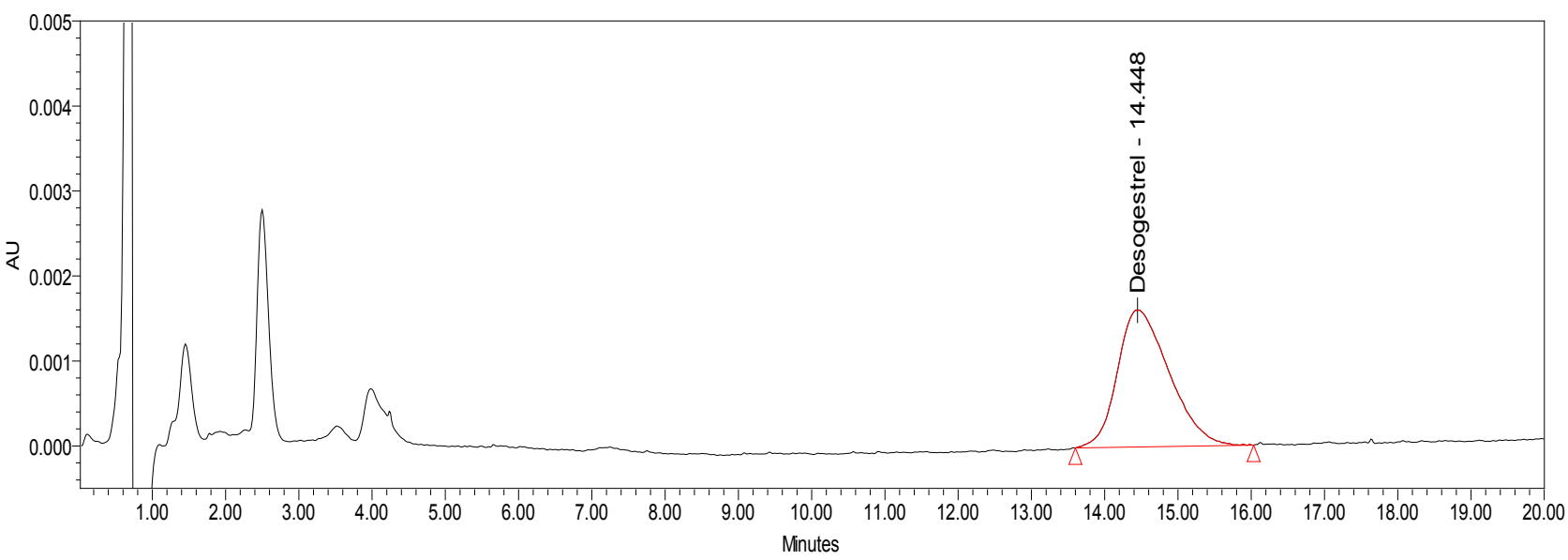

Figure 6: Chromatogram of Standard stock solution (UV detector). 
Citation: Bais S, Chandewar A, Popte I, Singhvi I, Gupta K (2013) Method Development and Validation for Desogestrel and Ethinylestradiol in Combined Pharmaceutical Dosage Form by RP-HPLC. Pharm Anal Acta 4: 262. doi:10.4172/2153-2435.1000262

Page 4 of 7

and found within acceptance criteria. Analytical method meets the acceptance criteria for Method Precision. Hence, the method is precise (Table 3 and 4 ).

Ruggedness (Intermediate precision): Ruggedness of method was verified by preparing two sets of content uniformity test preparation and six assay sample preparations from a single lot of Desogestrel and Ethinyloestradiol Tablets USP $(0.15 \mathrm{mg} / 0.03 \mathrm{mg})$ and analysed as per methodology by different analyst, by using different instrument (HPLC), different column, and different make of reagent and on a different day. Percentage of impurities was calculated. Content of Desogestrel and Ethinyloestradiol in Desogestrel and Ethinyloestradiol Tablets USP were calculated. Assay percentage of Desogestrel and Ethinyloestradiol in six assay sample preparations of Method Precision and Intermediate Precision was calculated and found within acceptance criteria as given in Table 5 and 6. Analytical method meets the acceptance criteria for Intermediate Precision (Ruggedness). Hence, method is precise and rugged.

\begin{tabular}{|c|c|c|c|c|}
\hline & Peak Name & RT $(\min )$ & Area $\left(\mu \mathrm{V}^{*}\right.$ sec $)$ & USP Tailing \\
\hline 1 & Desogestrel & 13.510 & 75432 & 1.18 \\
\hline 2 & Ethinyloestradiol & 2.445 & 469650 & 1.46 \\
\hline
\end{tabular}

Table 1: System suitability studies.

\begin{tabular}{|l|c|c|}
\hline \multirow{2}{*}{ Injection No. } & \multicolumn{2}{|c|}{ Area Response } \\
\cline { 2 - 3 } & Desogestrel & Ethinyloestradiol \\
\hline $\mathbf{1}$ & 75432 & 469650 \\
\hline $\mathbf{3}$ & 76564 & 468650 \\
\hline $\mathbf{4}$ & 76188 & 474215 \\
\hline $\mathbf{5}$ & 76282 & 485100 \\
\hline Average & 75821 & 486150 \\
\hline SD & 76058 & 476753 \\
\hline \% RSD & 76496.48 & 485127.5 \\
\hline
\end{tabular}

Table 2: System precision studies.

\begin{tabular}{|l|c|c|}
\hline \multirow{2}{*}{ Injection No. } & \multicolumn{2}{|c|}{ Area Response } \\
\cline { 2 - 3 } & Desogestrel & Ethinyloestradiol \\
\hline $\mathbf{1}$ & 73829 & 447030 \\
\hline $\mathbf{3}$ & 73723 & 447540 \\
\hline $\mathbf{4}$ & 73809 & 447890 \\
\hline $\mathbf{5}$ & 73629 & 447010 \\
\hline $\mathbf{6}$ & 73525 & 447639 \\
\hline Average & 73660 & 447271 \\
\hline SD & 73810 & 447400 \\
\hline \% RSD & 113.6981 & 318.3452 \\
\hline
\end{tabular}

Table 3: Method precision area.

\begin{tabular}{|l|c|c|}
\hline Observation No. & Assay of Desogestrel (\%) & Assay of Ethinyloestradiol (\%) \\
\hline 1. & 99.3 & 99.5 \\
\hline 2. & 99.5 & 99.2 \\
\hline 3. & 99.7 & 99.7 \\
\hline 4. & 99.3 & 101.1 \\
\hline 5. & 99.3 & 100.6 \\
\hline 6. & 98.7 & 101.6 \\
\hline Assay & $\mathbf{9 9 . 3}$ & $\mathbf{1 0 0 . 3}$ \\
\hline Minimum & $\mathbf{9 8 . 7}$ & $\mathbf{9 9 . 2}$ \\
\hline Maximum & $\mathbf{9 9 . 7}$ & $\mathbf{1 0 1 . 6}$ \\
\hline \% RSD & $\mathbf{0 . 3}$ & $\mathbf{0 . 9}$ \\
\hline
\end{tabular}

Table 4: Method precision data.

\begin{tabular}{|c|c|c|}
\hline Observation No. & $\begin{array}{l}\text { Assay of Desogestrel } \\
\text { (\%) SET I }\end{array}$ & $\begin{array}{l}\text { Assay of Desogestrel } \\
\text { (\%) SET II }\end{array}$ \\
\hline 1. & 99.3 & 98.9 \\
\hline 2. & 99.5 & 99.4 \\
\hline 3. & 99.7 & 98.5 \\
\hline 4. & 99.3 & 98.7 \\
\hline 5. & 99.3 & 98.6 \\
\hline 6. & 98.7 & 99.7 \\
\hline Assay & 99.3 & 99.0 \\
\hline Minimum & 98.7 & 98.5 \\
\hline Maximum & 99.7 & 99.7 \\
\hline$\%$ RSD & 0.3 & 0.5 \\
\hline \multirow[t]{3}{*}{$\begin{array}{l}\text { Overall \% RSD of results } \\
(N=12) \text { of two different sets }\end{array}$} & \multicolumn{2}{|c|}{0.4} \\
\hline & \multicolumn{2}{|c|}{ Ethinyloestradiol } \\
\hline & SET I & SET II \\
\hline 1. & 99.5 & 100.4 \\
\hline 2. & 99.2 & 99.5 \\
\hline 3. & 99.7 & 99.3 \\
\hline 4. & 101.1 & 101.5 \\
\hline 5. & 100.6 & 99.7 \\
\hline 6. & 101.6 & 99.9 \\
\hline Assay & 100.3 & 100.1 \\
\hline Minimum & 99.2 & 99.3 \\
\hline Maximum & 101.6 & 101.5 \\
\hline$\%$ RSD & 0.9 & 0.8 \\
\hline $\begin{array}{l}\text { Overall \% RSD of results } \\
(\mathrm{N}=12) \text { of two different sets }\end{array}$ & \multicolumn{2}{|c|}{0.9} \\
\hline
\end{tabular}

Table 5: Comparison between method precision and intermediate precision.

\begin{tabular}{|c|c|c|c|c|}
\hline \multirow[b]{2}{*}{ Level } & \multicolumn{2}{|c|}{ Desogestrel } & \multicolumn{2}{|c|}{ Ethinyl Estradiol } \\
\hline & $\begin{array}{c}\text { Concentration } \\
(\mu \mathrm{g} / \mathrm{mL})\end{array}$ & $\begin{array}{c}\text { Average Area } \\
\text { response }\end{array}$ & $\begin{array}{c}\text { Concentration } \\
(\mu \mathrm{g} / \mathrm{mL})\end{array}$ & $\begin{array}{c}\text { Average Area } \\
\text { response }\end{array}$ \\
\hline 50 & 0.3064 & 38983 & 0.06036 & 227772 \\
\hline 75 & 0.4596 & 57156 & 0.09054 & 329650 \\
\hline 100 & 0.6128 & 77449 & 0.12072 & 459720 \\
\hline 125 & 0.7660 & 97777 & 0.15090 & 571145 \\
\hline 150 & 0.9192 & 115030 & 0.18108 & 685265 \\
\hline 200 & 1.2256 & 151600 & 0.24144 & 904195 \\
\hline Slope & \multicolumn{2}{|c|}{123215} & \multicolumn{2}{|c|}{3769899} \\
\hline Intercept & \multicolumn{2}{|c|}{1575.5} & \multicolumn{2}{|c|}{-1328.1} \\
\hline $\begin{array}{l}\text { Correlation } \\
\text { coefficient }(r)\end{array}$ & \multicolumn{2}{|c|}{1.000} & \multicolumn{2}{|c|}{1.000} \\
\hline
\end{tabular}

\section{Study of linearity and range}

Preparation of stock solution and linearity level of Desogestrel: The $1500 \mathrm{mg}$ of working standard of Desogestrel transferred in $50 \mathrm{ml}$ of volumetric flask and diluted with $30 \mathrm{ml}$ of diluent and sonicated to dissolve, volume was made with diluent. From above solution linearity level of $10-150 \%$ for Desogestrel were prepared. (Conc. of Desogestrel $30000 \mathrm{mcg} / \mathrm{ml}$ ) as given in (Figure 7).

Preparation of stock solution and linearity level of Ethinyloestradiol: $75 \mathrm{mg}$ of working standard of Ethinylestradiol was transferred in $200 \mathrm{ml}$ of volumetric flask and dilute with $100 \mathrm{ml}$ of diluent and sonicated to dissolve, make up the volume with diluent. From above solution linearity level of $10-150 \%$ for Ethinyloestradiol were prepared. (Conc. of Ethinyloestradiol $375 \mathrm{mcg} / \mathrm{ml}$ ) Then each solution $(20 \mu \mathrm{L})$ was injected into the column and chromatographed using optimized chromatographic conditions. The corresponding chromatograms were recorded and area of each peaks for Desogestrel 
Citation: Bais S, Chandewar A, Popte I, Singhvi I, Gupta K (2013) Method Development and Validation for Desogestrel and Ethinylestradiol in Combined Pharmaceutical Dosage Form by RP-HPLC. Pharm Anal Acta 4: 262. doi:10.4172/2153-2435.1000262

Page 5 of 7

and Ethinyloestradiol were measured at $210.0 \mathrm{~nm}$. Each sample solution was chromatographed in triplicate and the mean peak area for Desogestrel and Ethinyloestradiol was calculated (Figure 8).

\section{Specificity}

Placebo interference study: Prepared the placebo solution by weighing equivalent amount of placebo present in the sample to be taken for assay preparation in triplicate, diluted it as per the test method and injected into the HPLC system. Evaluate the \% interference from placebo and recorded the observation as given in Table 7.

\section{Accuracy}

The accuracy of method was determined by recovery experiments. The recovery studies were carried out using standard addition method at 50, 100 and $150 \%$ level; known amount of standards was added to reanalyzed sample and subjected them to the proposed HPLC method. Percentage recovery was calculated from the amount found and actual amount added result shows in Table 8 and 9.

Standard stock solution (for Ethinyloestradiol): Accurately 37.5 $\mathrm{mg}$ of Ethinyloestradiol WS was weighed and transferred into a $50 \mathrm{ml}$ volumetric flask, add $30 \mathrm{ml}$ of diluent and sonicated to dissolve, then diluted up to the mark with diluent and mixed well. Then make it up to

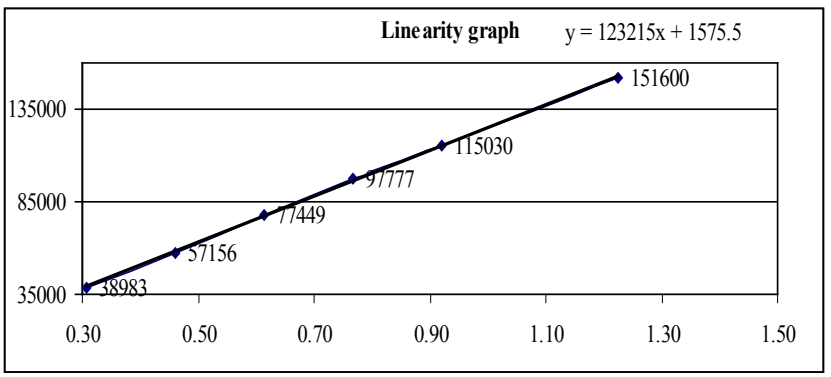

Figure 7: Linearity graph for Desogestrel.

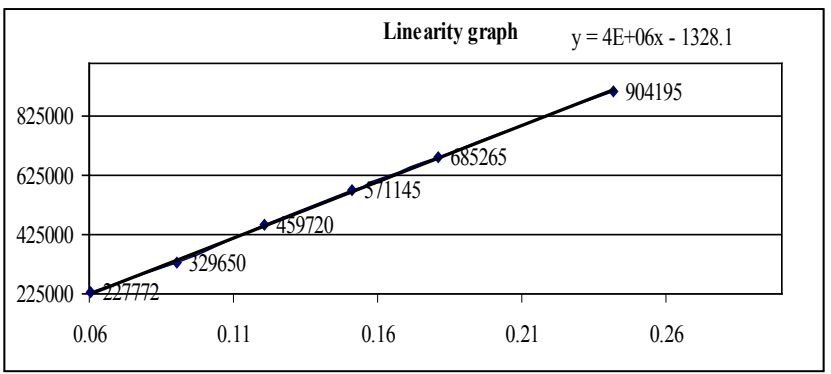

Figure 8: Linearity graph for Ethinyloestradiol.

\begin{tabular}{|l|c|c|c|c|}
\hline \multirow{2}{*}{ Sr. No. } & \multicolumn{2}{|c|}{ Desogestrel } & \multicolumn{2}{c|}{ Ethinyloestradiol } \\
\cline { 2 - 5 } & Assay $(\mathbf{m g})$ & Assay \% of LC & Assay (mg) & Assay \% of LC \\
\hline $\mathbf{1}$ & 74.41 & 99.2 & 0.783 & 104.5 \\
\hline $\mathbf{2}$ & 74.72 & 99.6 & 0.798 & 106.5 \\
\hline 3 & 74.62 & 99.7 & 0.789 & 105.2 \\
\hline Average & 74.6 & 99.5 & 0.790 & 105.4 \\
\hline SD & 0.1582 & 0.2646 & 0.0075 & 0.8544 \\
\hline \% RSD & 0.2 & 0.3 & 1.0 & 0.8 \\
\hline
\end{tabular}

Table 7: Results and statistical data for estimation of DESO and ETHY in marketed formulation. the mark with diluent.

Mixed standard preparation: Weigh accurately $150 \mathrm{mg}$ of Desogestrel working standard into a $20 \mathrm{ml}$ volumetric flask, add $5 \mathrm{ml}$ of diluent and sonicate to dissolve. The Ethinyloestradiol $2 \mathrm{ml}$ stock solution was added and mixed well. The volume was made up to the mark with diluent.

\section{Sample preparation}

Accuracy: The samples were prepared by adding active ingredients into the placebo at different concentrations or spiking the solution on placebo $(50 \%, 100 \%$, and $150 \%)$ each in triplicate. Injected each preparation into the HPLC system.

Procedure: The standard preparation and sample preparations were injected for recovery solutions into the chromatograph and the peak responses were measured for the major peaks. The system suitability was checked and the results were recorded.

\section{Application of Proposed Method for Estimation of Desogestrel and Ethinylestradiol on Marketed Tablet Formulation}

\section{Test preparation}

The 20 tablets was weighed and transferred to $200.00 \mathrm{ml}$ volumetric flask, $120 \mathrm{ml}$ of diluents was added, the stopper was inserted and sonicated with intermittent shaking for 30 minutes. Volume was made with diluent and shaken. A portion of this solution was centrifuged at $3000 \mathrm{RPM}$ for 10 minutes. $2.00 \mathrm{ml}$ of resulting solution was transferred to $50.00 \mathrm{ml}$ volumetric flask; the volume was made with diluent and shake. Such two sample preparation was prepared. (Desogestrel 0.6 $\mathrm{mcg} / \mathrm{ml}$ and Ethinyloestradiol $0.12 \mathrm{mcg} / \mathrm{ml}$ ) as given in Table 8 and 9.

\section{Procedure and system suitability for content uniformity test}

The column was equilibrated with the mobile phase with chromatographic condition for the proper baseline. First injected diluent as blank (one injection). Then injected standard preparation-I (one injection) and checked the system suitability parameter as given below (A). Then standard preparation-II was injected (one injection) and checks the similarity factor as given below (B). After getting the satisfactory result, standard preparation-II was injected (four injections), check relative standard deviation of five replicate injections of standard preparation-II as given below (C), diluents was injected as blank (one injection). Then proceed for duplicate injections of assay test preparation but inject one injection of standard preparation-II as bracketing standard after each five injections of test preparation and check the relative standard deviation as given below (D).

A. Tailing factor for Desogestrel and Ethinyloestradiol should Not be more than 2.0

B. Similarity factor between area of standard preparation-I and standard preparation-II should be 0.98 to 1.02

Area of standard $-\mathrm{I} \times$ Weight of standard - II Area of first injection of standard - II $\times$ Weight of standard - I

C. Relative standard deviation of 5 replicate injections of standard preparation-II should Not be more than $2.0 \%$

D. Relative standard deviation between 5 replicate injections and bracketing standards should Not be more than $2.0 \%$ 
Citation: Bais S, Chandewar A, Popte I, Singhvi I, Gupta K (2013) Method Development and Validation for Desogestrel and Ethinylestradiol in Combined Pharmaceutical Dosage Form by RP-HPLC. Pharm Anal Acta 4: 262. doi:10.4172/2153-2435.1000262

Page 6 of 7

\begin{tabular}{|c|c|c|c|c|c|}
\hline \multirow{2}{*}{ Recovery level } & \multicolumn{5}{|c|}{ Desogestrel With Placebo } \\
\hline & Amount added (mcg / ppm) & Amount recovered (mcg / ppm) & \% Recovery & Average recovery & $\%$ RSD \\
\hline \multirow{3}{*}{$70 \%$} & 0.4168 & 0.4220 & 101.2 & \multirow{3}{*}{101.3} & \multirow{3}{*}{0.3} \\
\hline & 0.4168 & 0.4235 & 101.6 & & \\
\hline & 0.4168 & 0.4208 & 101.0 & & \\
\hline \multirow{3}{*}{$100 \%$} & 0.5954 & 0.6041 & 101.5 & \multirow{3}{*}{100.8} & \multirow{3}{*}{0.6} \\
\hline & 0.5954 & 0.6002 & 100.8 & & \\
\hline & 0.5954 & 0.5963 & 100.2 & & \\
\hline \multirow{3}{*}{$130 \%$} & 0.7740 & 0.7718 & 99.7 & \multirow{3}{*}{99.7} & \multirow{3}{*}{0.1} \\
\hline & 0.7740 & 0.7719 & 99.7 & & \\
\hline & 0.7740 & 0.7728 & 99.8 & & \\
\hline \multicolumn{4}{|c|}{ Overall } & 100.6 & 0.33 \\
\hline
\end{tabular}

Table 8: Recovery data for desogestrel.

\begin{tabular}{|c|c|c|c|c|c|}
\hline \multirow{2}{*}{ Recovery level } & \multicolumn{5}{|c|}{ Ethinyloestradiol With Placebo } \\
\hline & Amount added (mg / ppm) & Amount recovered (mg / ppm) & \% Recovery & Average recovery & $\%$ RSD \\
\hline \multirow{3}{*}{$70 \%$} & 0.0835 & 0.0831 & 99.5 & \multirow{3}{*}{99.7} & \multirow{3}{*}{0.4} \\
\hline & 0.0835 & 0.0836 & 100.1 & & \\
\hline & 0.0835 & 0.0830 & 99.4 & & \\
\hline \multirow{3}{*}{$100 \%$} & 0.1192 & 0.1209 & 101.4 & \multirow{3}{*}{101.5} & \multirow{3}{*}{0.2} \\
\hline & 0.1192 & 0.1210 & 101.5 & & \\
\hline & 0.1192 & 0.1212 & 101.7 & & \\
\hline \multirow{3}{*}{$130 \%$} & 0.1550 & 0.1562 & 100.8 & \multirow{3}{*}{101.2} & \multirow{3}{*}{0.3} \\
\hline & 0.1550 & 0.1568 & 101.2 & & \\
\hline & 0.1550 & 0.1573 & 101.5 & & \\
\hline \multicolumn{4}{|c|}{ Overall } & 100.8 & 0.33 \\
\hline
\end{tabular}

Table 9: Recovery data for Ethinyloestradiol.

\section{Conclusion}

From the studies it can be concluded that RP-HPLC technique can be successfully used for the estimation of Desogestrel and Ethinylestradiol in their combined dosage Tablet formulations. The method shows good reproducibility compared to UV-spectrophotometric methods. The RP-HPLC method is accurate, precise, specific, reproducible and sensitive. No interference of additives, matrix etc. is encountered in these methods. Further studies on other pharmaceutical formulations would throw more light on these studies. The methods were found to be sensitive, reliable, reproducible, rapid and economic also.

\section{References}

1. Maryadele J, Ann S, editors (2006) The Merck Index, An Encyclopedia Of Chemical, Drug's and Biologicals, (13thedn), White House Station.NJ: Merck and Co, Inc : 1603

2. Farhad A, Ramin GM (2004) Determination of levonorgestrel and ethinyl estradiol in pharmaceutical formulations by $\mathrm{H}$-point standard addi-tion method in nonaqueous solvent using simultaneous addition of both analytes, Journal of Reports in Pharmaceutical SciencesV 1: 6-14

3. Szabó A (1977) [A technic for the determination of ethinyl estradiol and norgestrel]. Acta Pharm Hung 47: 24-28.

4. Strusiak SH, Hoogerheide JG, Gardner MS (1982) Determination of ethinyl estradiol in solid dosage forms by high-performance liquid chromatography. $J$ Pharm Sci 71: 636-640

5. Weston A, Brown PR (1997) High Performance Liquid Chromatography, Separations in High Performance Liquid Chromatography, Instrumentation for HPLC. In: HPLC and CE - Principles and practice. Academic Press, USA

6. Prabhakar B, Deshpande SG (1999) Simultaneous estimation of Ethinyloestradiol and levonorgestrel from transdermal patches by HPLC. IJPS 61: $12-15$.

7. Fakhari AR, Khorrami AR, Shamsipur M (2006) Stability-indicating highperformance thin-layer chromatographic determination of levonorgestrel and ethinyloestradiol in bulk drug and in low-dosage oral contraceptives. Anal Chim Acta 572: 237-242.
8. Durga PS, Changala R, Prasad PSS, Mukkanti K (2004) Simultaneous HPLC Estimation Of Levonorgestrel And Ethinyloestradiol From Tablets. Indian Journal of Pharmaceutical sciences 66: 231-234.

9. Matejícek D, Kubán V (2007) High performance liquid chromatography/ ion-trap mass spectrometry for separation and simultaneous determination of ethynylestradiol, gestodene, levonorgestrel, cyproterone acetate and desogestrel. Anal Chim Acta 588: 304-315.

10. Van DR, Eickhoff WM, John KJ, Nicholas J (1987) Automated stability indicating high performance HPLC assay for Ethinyloestradiol and Levonorgestryl tablets. Pharmaceutical Research 4: 54-58.

11. Sarat M, Rambabu C (2012) A validated simultaneous RP-HPLC method for determination of Desogestrel and ethinyl estradiol tablets. International journal of pharmacy and pharmaceutical sciences 4:115-119.

12. Parmar AR, Raval TD, Bhakhar DN, Shah DK, Dobariya SD (2012) Development and validation of RP-HPLC method for estimation of drospirenone and Ethinyloestradiol in its tablet dosage forms. Inventi Rapid: Pharm Analysis \& Quality Assurance.

13. Berzas JJ, Rodríguez J, Castañeda G (1997) Simultaneous determination of ethinylestradiol and levonorgestrel in oral contraceptives by derivative spectrophotometry. Analyst 122: 41-44.

14. Markopoulou CK, Koundourellis JE (2006) Development of a validated liquid chromatography method for the simultaneous determination of Ethinyloestradiol, cyproterone acetate, and norgestrel in breast milk following solid-phase extraction. J Liq Chromatogr Relat Technol 29: 685-700.

15. Li F, Hsieh Y, Korfmacher WA (2008) High-performance liquid chromatographyatmospheric pressure photoionization/tandem mass spectrometry for the detection of 17alpha-ethinylestradiol in hepatocytes. J Chromatogr B Analyt Technol Biomed Life Sci 870: 186-191.

16. Liu XF, Ding CG, Ge QH, Zhou Z, Zhi XJ (2010) [Simultaneous determination of gestodene, etonogestrel and ethinylestradiol in plasma by LC-MS/MS following derivatization]. Yao Xue Xue Bao 45: 87-92.

17. Eldawy MA, Tawfik AS, Elshabouri SR (1975) Rapid, sensitive colorimetric method for determination of ethinyl estradiol. J Pharm Sci 64: 1221-1223.

18. Peinado A, Hammond J, Scott A (2011) Development, validation and transfer of a near infrared method to determine in-line the end point of a fluidised drying 
Citation: Bais S, Chandewar A, Popte I, Singhvi I, Gupta K (2013) Method Development and Validation for Desogestrel and Ethinylestradiol in Combined Pharmaceutical Dosage Form by RP-HPLC. Pharm Anal Acta 4: 262. doi:10.4172/2153-2435.1000262

Page 7 of 7

process for commercial production batches of an approved oral solid dose pharmaceutical product. J Pharm Biomed Anal 54: 13-20.
19. ICH (1994) Q2A, Text on Validation of Analytical Procedures. International Conference on Harmonization, Geneva. 